\title{
Tips for Overcoming the Publication Challenges Faced by Young Researchers
}

\author{
Balachandra V Adkoli \\ Keywords: Copyright, Plagiarism, Research publication, Scientific misconduct, Scientific writing. \\ Annals of SBV (2019): 10.5005/jp-journals-10085-8118
}

In the opening issue of Annals of SBV, we made a modest beginning by publishing a handful of review articles on diverse issues in medical science. Happily, a large volume of information is now available on tips for writing a good review article ${ }^{1}$ or for that matter any type of article in a befitting manner. ${ }^{2}$ However, for a young researcher, one can anticipate some teething problems in achieving successful acceptance. There are challenges not only for the young researchers but also the editorial team and the publishing houses, which are constantly bringing desirable changes to face stiff competition in the world of scientific publication.

We need to address the interplay of several steps, beginning with the preparation and submission of the manuscript, editorial review and correspondence, till the final production in electronic or print form. The entire process involves several stakeholders: the authors, editors, reviewers, besides the production staff who constitute the "cogwheel" in the publication process. The possibility of a manuscript turning into successful publication depends largely upon the "processes" that we must address in the larger interest of research publication.

A good manuscript that editors want is a perfect shot, which combines several factors: the relevance of the paper, originality, potentiality to improve the practice or advance knowledge, truthful and ethical manner in which the data are presented in a clear and concise language, besides some "wow factors" to excite the readers. ${ }^{3}$ Assuming that the authors have done a good job in preparing the manuscript, one is not sure, whether it would be acceptable to a journal that has its own requirements. It is, therefore, desirable to study the journal's requirement and consult a colleague or a potential reader to critique the manuscript before submission. This should be combined with a self-evaluation of strengths and weaknesses of the paper to decide the journal for submission. What is the type of article? Is it a review, original article, or brief communication? Who are the target audience for the paper? What is the scope of the journal? Is it indexed or nonindexed? What is its impact factor? Is it a national or international journal? Is it open access or paid? What is its periodicity? Is it printed or e-journal? Unless one addresses all these issues, one is likely to get frustrated in the event of rejection.

Rejection happens for various reasons. It is not necessary that the paper is of poor quality. It could be due to the mismatch between the journals' requirement and the article's focus. Sometimes there could be issues with the peer-review process. It is therefore necessary to "accept rejection" and start working on the comments made. It is always good practice to revise the paper and resubmit, along with a pointwise clarification about the revision and justification for the status quo. Some experts suggest that based on the comments made by the reviewers, one can revise the paper
Centre for Health Professions Education, Sri Balaji Vidyapeeth (Deemed to be University), Puducherry, India

Corresponding Author: Balachandra V Adkoli, Centre for Health Professions Education, Sri Balaji Vidyapeeth (Deemed to be University), Puducherry, India, Phone: +91 9873029295, e-mail: balachandraa@ mgmcri.ac.in

How to cite this article: Adkoli BV. Tips for Overcoming the Publication Challenges Faced by Young Researchers. Ann SBV 2019;8(2):24-25.

Source of support: Nil

Conflict of interest: The author is the Chief Editor of the journal.

and send it to some other journal that fits into the work. Even in that case, it is good practice to admit that the paper was rejected for a particular reason that has been addressed now. The publication ethics condemns simultaneous submission of a paper to multiple journals, which should be kept in mind before submission.

Deciding and declaring the author contribution is often a bone of contention. The guidelines issued by the International Committee of Medical Journal Editors (ICMJE) are very clear about the rights for authorship. ${ }^{4}$ Unless the authors make substantial contribution toward conception, data collection, analysis, drafting, and reviewing the draft, they can't be listed as authors. Since the corresponding author takes the responsibility for the paper, his/her role becomes crucial during the editorial and the publication process. While the junior writers are often hesitant to claim their rightful place as the first author (primary), it is the moral duty of senior authors to empower them to do so, and take up the role as coauthors and correspondence authors.

The next issue that is plaguing the scientific publication is related to data fabrication and falsification. Research scholars are often averse to declare negative findings. This is not in the spirit of science. Moreover, negative findings at times may be eye-openers for giving new twist to the story. The scientists should therefore make it a habit to avoid falsification and fabrication of data and come out openly with the "limitations of the study" before they are caught by the reviewers.

The last but the most important issue is the trap of plagiarism, which has become a bane for the scientific world. Plagiarism is nothing but a "theft" of idea, process, or results from other's work without giving appropriate credit. It can affect one's reputation and even cost a job in a prestigious organization. Plagiarism is the result of rising ambition to churn out publications, since publication has often become the sole criteria of promotion. While this needs to be addressed, the immediate measure needed is to train and empower the young researchers in original writing. While such a discussion is beyond the scope of this article, I propose step-wise "5-R approach"

( The Author(s). 2019 Open Access This article is distributed under the terms of the Creative Commons Attribution 4.0 International License (https://creativecommons. org/licenses/by-nc/4.0/), which permits unrestricted use, distribution, and non-commercial reproduction in any medium, provided you give appropriate credit to the original author(s) and the source, provide a link to the Creative Commons license, and indicate if changes were made. The Creative Commons Public Domain Dedication waiver (http://creativecommons.org/publicdomain/zero/1.0/) applies to the data made available in this article, unless otherwise stated. 
as follows: (1) Research the source of information available on the Internet and elsewhere, paying attention to copyright issues (free access, limited access, or paid) and download or write to the person who holds copyright. (2) Review carefully and write down with paper and pencil (or using free software like paint in case you are tech-savvy and eco-friendly!). (3) Reflect upon your focus of study, what you need to selectively assimilate. (4) Recreate or rewrite the text based on your template. (5) Recognize, which means that you should profusely acknowledge the contribution of others through citations as per the style of the journal. This approach will result in showcasing your originality, which is the heart of scientific writing.

While a number of plagiarism softwares are now available, what is needed is a mechanism to teach the "tricks of the trade" to the junior researchers in coming out of the trap of plagiarism. Steps are needed at the level of senior researchers, journal editorial boards, and publication staff to induct and promote the habits of scientific honesty and help the junior researchers to come out of the "copy and paste" technique!

In summary, the challenges of achieving a good scientific stuff can be faced by a collective and concerted movement by all concerned. While the young researchers are now placed at the receiving end, the seniors, the editorial board, the reviewer community, and the publication staff have equal responsibility to mentor, coach, handhold, and empower the younger generation who are our future scientific assets. This is what we aspire from vibrant journals like Annals of SBV.

\section{References}

1. Mayer P, Zurich-Basel Plant Science Center: Guidelines for writing a Review Article. Universität Zurich (2009) Available at http://www. plantscience.ethz.ch/education/Masters/courses/Scientific_Writing.

2. Parija SC, Kate V, ed. Thesis Writing for Master's and Ph.D. Program Springer 2018.

3. How to write a world class medical paper-Tips, Traps and Travesties; S\&T, Elsevier China Available at https://medicine.umich.edu/sites/ default/files/content/downloads/Elsevier.How\%20to\%20write\%20 a\%20world-class\%20paper.pdf.

4. International Committee of Medical Journal Editors (ICMJE). Defining the Role of Authors and Contributors. Available at http://www.icmje. org/recommendations/browse/roles-and-responsibilities/definingthe-role-of-authors-and-contributors.html. 